\title{
Avaliação do Comportamento Mecânico de Misturas Asfálticas do Tipo CPA com Incorporação de PEBD no Ligante Betuminoso CAP 50/70
}

DOI: http://dx.doi.org/10.18616/civiltec.v2i1.5356

Karini Boneli Silva ${ }^{1}$

Luiz Renato Steiner ${ }^{2}$

\section{Introdução}

No Brasil, mais de $60 \%$ das mercadorias e dos passageiros são transportados por rodovias. Para Queiroz (2016), devido à importância do transporte rodoviário, é necessária a concepção de pavimentos que conservem a sua vida útil e proporcionem aos seus usuários conforto e segurança. No País, quase em sua totalidade, os pavimentos rodoviários são do tipo flexíveis, com estrutura formada por camadas superpostas de material pétreo e, sobre elas, um revestimento à base de Cimento Asfáltico de Petróleo (CAP). Segundo Bernucci et al. (2006), os CAPs convencionais possuem os requisitos necessários para um bom desempenho das misturas asfálticas. No entanto, com o crescente aumento da frota, das cargas e das condições adversas do clima, cada vez mais se buscam alternativas para melhorar ou modificar as propriedades dos asfaltos. Atualmente, são estudados e empregados polímeros que melhoram o desempenho desses ligantes, dos quais, segundo Negrão (2006), os mais utilizados são os SBS (copolímero de estireno butadieno), SBR (Borracha de butadieno estireno), EVA (Copolímero de etileno acetato de vinila) e o RET (Coluna de etileno com dois copolímeros acoplados). Além desses, muitos estão presentes na vida cotidiana, como o PEBD (polietileno de baixa densidade), encontrado em sacolas plásticas. Para Yildirim (2007), os asfaltos modificados com polímeros apresentam meIhor resistência à deformação permanente e ao trincamento térmico, consequentemente aumentando a vida útil do pavimento. Nesse contexto, o presente trabalho teve como objetivo a incorporação do PEBD ao CAP convencional na forma de reciclado de sacolas plásticas, avaliando seu efeito nas propriedades físicas e mecânicas de misturas asfálticas do tipo CPA - Camada Porosa de Atrito.

\footnotetext{
${ }^{1}$ Bacharel em Engenharia Civil, Universidade do Extremo Sul Catarinense, ka_boneli@hotmail.com

${ }^{2}$ Mestre em Engenharia de Materiais, Universidade do Extremo Sul Catarinense, luizsteiner@unesc.net
} 
Para alcançar os objetivos da pesquisa, foi elaborado um programa experimental utilizando-se a metodologia de dosagem Marshall (DNER-ME 043/95), que visa buscar o teor ideal de ligante (\% CAP) e o volume de vazios (\% Vv) em uma mistura asfáltica. Primeiramente, foi realizada a caracterização dos agregados pétreos conforme as especificações para uma mistura asfáltica do tipo CPA, com seu enquadramento dentro da Faixa II (DNER-ES 386/99). Em seguida, foram definidas as proporções dos agregados pétreos para quatro traços de misturas com teores de ligante de 4,0, 4,5, 5,0, 5,5 e 6,0\%. A primeira composição foi denominada traço de referência composta por agregados e ligante asfalto-borracha TIREFLEX AB8. Os demais conjuntos de misturas foram compostos de agregados e CAP 50/70 com incorporação prévia de 3, 5 e $7 \%$ de $\mathrm{PEBD}$ em substituição à massa do ligante convencional. O ligante modificado com os diferentes \% PEBD também foi avaliado quanto à sua adesividade ao agregado (DNER-ME 078/94) e à penetração (DNIT 155/2010). Após definido o \% CAP ideal das misturas estudadas, foram confeccionados novos corpos de prova para cada traço, sendo três para ensaio de cântabro, três para ensaio de permeabilidade vertical/horizontal e três para resistência à compressão diametral.

\section{Resultados}

Os resultados de adesividade do ligante ao agregado mostram que além do ligante TIREFLEX AB8, as amostras de CAP 50/70 com 3, 5 e 7\% de PEBD também apresentaram resultados satisfatórios, sem deslocamento da película betuminosa. Com relação aos resultados de penetração, Figura 1, as amostras com 3, 5 e 7\% de PEBD obtiveram resultados de 19, 21 e $14(0,1 \mathrm{~mm})$, respectivamente, contra $52(0,1 \mathrm{~mm})$ da amostra de referência, ou seja, o PEBD impôs maior consistência e rigidez ao ligante convencional. Nos resultados de permeabilidade, Figura 2, tanto a amostra de referência como as amostras com PEBD apresentaram permeabilidade horizontal superior à vertical, efeito esse desejado, pois facilita a drenagem da água para os bordos da pista. Todas as amostras obtiveram permeabilidade vertical/horizontal superior a $0,116 \mathrm{~cm} \cdot \mathrm{s}^{-1}$ ou superior ao recomendado pela ASTM D7064-13 (2013 apud JACQUES, 2018), porém o PEBD nos teores de 3 e 5\% provocou uma redução nos vazios comunicantes. Perante o desgaste ao cântabro, Tabela 1, os resultados atenderam às especificações da DNER-ES 383/99 de no máximo $25 \%$, sendo as amostras de PEBD com uma média de $17,9 \%$ contra $22,36 \%$ da amostra de referência, indicando uma maior coesão das amostras com ligante misturado ao PEBD. Para os resultados de resistência à tração por compressão diametral, Tabela 1, foi observado um ganho de $26 \%$ 


\section{Revista Técnico-Cientifica}

para as amostras de PEBD até o teor de $5 \%$ em relação à referência, sendo $30 \%$ inferior para a amostra com $7 \%$ de PEBD, devido à maior rigidez

e ao maior $\% \mathrm{Vv}$ apresentado pela mistura. Todas as misturas estudadas não atenderam às especificações da DNER-ES 386/99 de no mínimo 5,5kgf cm-2.

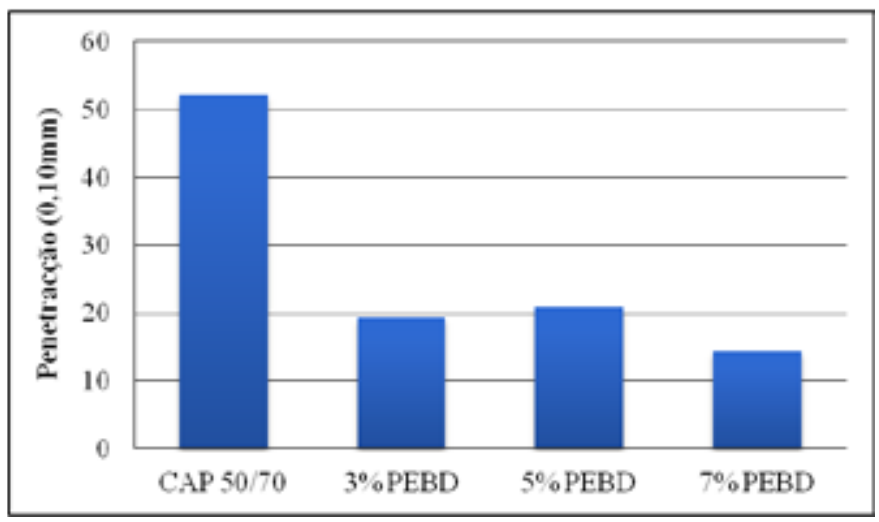

Figura 1 - Resultados ensaio de penetração

Fonte: Elaborada pelos autores.

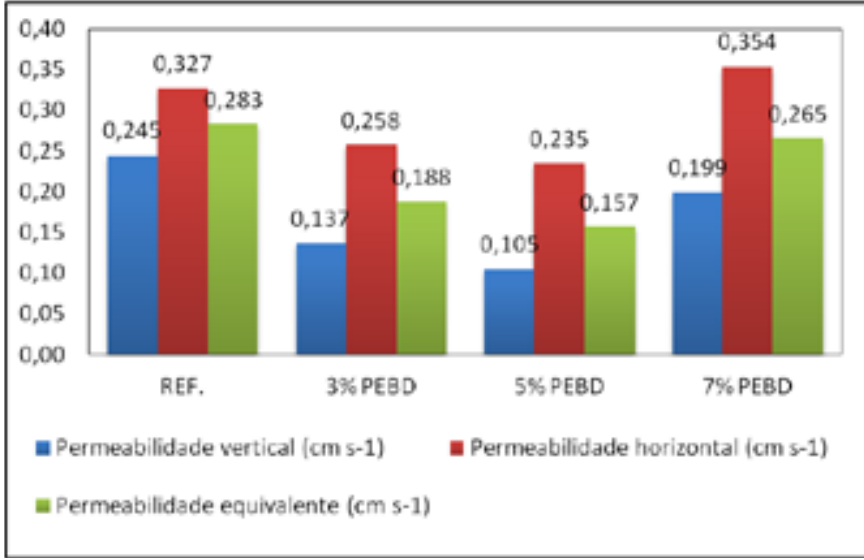

Figura 2 - Valores médios das permeabilidades vertical, horizontal e equivalente

Fonte: Elaborada pelos autores. 


\begin{tabular}{cccc}
\hline & $\begin{array}{c}\text { Teor de ligante } \\
(\%)\end{array}$ & $\begin{array}{c}\text { Cântabro } \\
(\%)\end{array}$ & $\begin{array}{c}\text { Resistência à tração por } \\
\text { compressão diametral } \\
\left(\mathrm{kgf} \mathrm{cm}^{-2}\right)\end{array}$ \\
\hline REF. & 5,0 & 22,36 & 2,44 \\
3\% PEBD & 5,5 & 19,61 & 2,70 \\
5\% PEBD & 5,5 & 16,26 & 3,07 \\
7\% PEBD & 5,5 & 17,83 & 1,71 \\
\hline Especificação DNER-ES 386/99 & $<25,00$ & $>5,50$ \\
\hline
\end{tabular}

Tabela 1 - Resultado dos ensaios de cântabro e resistência à tração por compressão diametral

Fonte: Elaborada pelos autores.

\section{Conclusão}

O desempenho das misturas asfálticas tipo CPA com o polímero PEBD no ligante convencional CAP 50/70 é comparado com uma mistura moldada com ligante asfáltico modificado por borracha (TYREFLEX AB8). A incorporação do PEBD ao ligante convencional em todos os teores estudados provoca um aumento da consistência e da rigidez deste, tornando o CAP 50/70 menos suscetível ao calor e às deformações plásticas. A adição do PEBD reduz a densidade aparente das misturas devido à baixa densidade do polímero em relação a outros constituintes delas e também promove um aumento no \%Vv. Apesar de os teores de 3 e $5 \%$ reduzirem os vazios comunicantes, as amostras apresentam uma permeabilidade superior ao recomendado pelas especificações. O PEBD aumenta a coesão das misturas tipo CPA, mantendo o esqueleto pétreo mais estável e mais resistente ao desgaste à passagem dos rodados. Destaca-se que, com a incorporação de PEBD ao ligante asfáltico, ele promove boa adesividade do ligante ao agregado, melhorando as propriedades físicas e mecânicas das misturas do tipo CPA, com boa empregabilidade para tráfegos mais pesados, promovendo um aumento da durabilidade dos pavimentos.

Palavras-chave: Pavimento; Cimento Asfáltico; Polímero.

\section{Referências}

BERNUCCI, L. B.; MOTTA, L. M. G.; CERATTI, J. A. P.; SOARES, J. B. Pavimentação asfáltica: formação básica para engenheiros. Rio de Janeiro: Petrobras/Abeda, 2006. 504 p.

DEPARTAMENTO NACIONAL DE ESTRADAS DE RODAGEM - DNER. DNER-ES 386/99: Pavimentação - pré-misturado a quente com asfalto polímero - camada porosa de atrito. Rio de Janeiro: Departamento Nacional de Estradas de Rodagem, 1999. 
DEPARTAMENTO NACIONAL DE ESTRADAS DE RODAGEM - DNER. DNER-

ME 043/95: Misturas betuminosas a quente - ensaio Marshall. Rio de Janeiro: Departamento Nacional de Estradas de Rodagem, 1995.

DEPARTAMENTO NACIONAL DE ESTRADAS DE RODAGEM - DNER. DNER-ME 078/94: Agregado graúdo - adesividade a ligante betuminoso. Rio de Janeiro: Departamento Nacional de Estradas de Rodagem, 1994.

DEPARTAMENTO NACIONAL DE INFRAESTRUTURA DE TRANSPORTES - DNIT. DNIT 155/2010: Material asfáltico - Determinação da penetração - Método de ensaio. Rio de Janeiro: Departamento Nacional de Infraestrutura de Transportes, 2010.

JACQUES, G. E. Aplicabilidade de misturas mornas em revestimentos do tipo camada porosa de atrito (CPA). 2018. 111 f. Dissertação (Mestrado em Engenharia Civil, Construção e Infraestrutura) - Universidade Federal do Rio Grande do Sul, Porto Alegre, 2018.

NEGRÃO, D. P. Estudo de asfaltos modificados por polímeros do tipo RET para aplicações em pavimentos. 2006. Dissertação (Mestrado) - Universidade de São Paulo, São Paulo, 2006.

QUEIROZ, B. O. Avaliação do desempenho de misturas asfálticas porosas modificadas com politereftalato de etileno (PET). 2016. 125 f. Dissertação (Mestrado em Engenharia Civil e Ambiental) - Universidade Federal da Paraíba, João Pessoa, 2016.

YILDIRIM, Y. Polymer modified asphalt binders. Construction and Building Materials, n. 21, p. 66-72, 2007. 